\title{
OPEN-MOUTHED WONDER - AN ACCOUNT OF METONYMY-BASED COMPOUND EPITHETS
}

Compound epithets tend to be widely used in contemporary fiction and are thoroughly addressed by rhetoric and stylistic studies. Still, there are few linguistic accounts for these creative utterances in cases when they are based on metonymical shifts. The paper aims to account for the applicability of Conceptual integration theory to metonymy-based compound epithets. The goal is to demonstrate the process of cross-mapping of mental spaces in cases of compound epithet metonymy. By using the fictional discourse examples dependant on the context, we shall provide an explanation for the process behind these metonymical constructions in terms of cross-mapping of different mental spaces.

Key words: compound epithets, metonymy, conceptual integration, crossmapping, blend.

\section{Introduction}

Epithets have long been considered as one of most frequent stylistic devices. They are certainly not new to either global or English literature. The epithet is a means based on the interplay between emotional and logical meanings, which tends to be subjective and evaluative. Definitions of epithets are many - from those referring to it as a word or a phrase reflecting individual perception of authors instead of plainly defining an object or a phenomenon (Karavaeva, 2009) to those claiming that an epithet is a subjective connection with the object being described (Simpson, 2004). If we, for a moment, set the theory aside, a conclusion arises that epithets largely depend on creativity, perception and intention of those who create them. What is interesting is that once we use adjectives (in the paper referred to as epithets for their function and not form), which regularly tend to be lexicalized, in a work of written art, they inspire completely new sensations even though they do not result in new lexical meanings. The 
taxonomy of epithets based on the semantic criterion has been addressed in a large body of work (Galperin 1997; Onoprienko 2002). Among epithets based on metaphor, comparison or hyperbole, we shall focus on compound metonymy-based epithets.

Compound epithets represent neither linguistic nor literary phenomenon of a recent date. They were well-recognized in ancient epic drama as Homer used them to introduce picturesque images. He was wellknown for his "combinations of adjectives and nouns which we nowadays refer to as Homeric epithets" (Beckson and Ganz, 1960: 55)". Today, we "categorize them as compound epithets; they tend to have figurative meaning and they point out the metaphorical dimension of language" (Sakran, 2005: 4). Homeric epithets were embraced by English poets and writers such as Shakespeare, Milton and Spenser. Eventually, compound such as all-seeing and bitter-sweet were lexicalized and their usage became ordinary. Still, contemporary writers also tend to rely on them in order to achieve valuable and vivid effects. Modern stylistics recognizes different classification of epithets based on semantic criterion. A most general one was offered by Karavaeva (2009) who semantically distinguishes between two types of epithets: emotional and figurative.

Speaking of compound epithets and their figurative occurrence, we shall focus on those whose figurative meaning arises from the metonymical shifts based on contiguity relations between the modified noun and the original noun from which the epithet is transferred. Now, we come to what is referred to as transferred epithet which is an effective stylistic device resulting from the "abuse" of traditional grammatical rules. In this regard, among many definitions of transferred epithets offered by different scholars, Lanham pointed out that "transferred epithet is a change in the relation of words by which a word, instead of agreeing with the case it logically qualifies, is made grammatically with another case" (1991:86). Furthermore, A Dictionary of Literary Terms (Cuddon, J. A, 1979:315) defines transferred epithet as "a figure of speech in which the epithet is transferred from the appropriate noun to modify another to which it does not really belong". There have been recent studies on transferred epithet offering a constructionist approach (Shibuya, 2006) and description of semantic mechanisms (Barancheeva, 2016). Still, we believe that traditional approaches cannot account for these metonymical constructions as detailed as integration theory can. 
In addition, the paper addresses not all types of transferred epithet but rather those examples in which compound-adjectives represent left constituents. For the purpose of the paper, the term metonymy-based compound epithet will be adopted precisely to point out the nature of the left constituent. Namely, there is a strong reason why we shall account for those metonymy-based epithets (transferred epithets) where the noun is modified by a compound adjective. Transferred epithets are powerful stylistic devices which result in effective utterances ranging from comic to bombastic ones. Compound adjectives in these utterances may only contribute to the expressiveness of construction and make it even more powerful. We may refer to these compounds as words tightly-packed with meaning as they are space-saving, eye-catching paraphrases.

\section{Metonymy}

Classical rhetoric recognized up to 250 stylistic devices, including metonymy. Later on, Roman Jacobson and his structuralism studied tropes by connecting them with different art movements on one side and different cognitive processes on the other. More specifically, Jacobson narrowed rhetoric down to two single tropes, metaphor and metonymy, for which he believed to have been universal semiotic mechanisms. Each stylistic device possesses at least one quality based on which it is generated. Metonymy had long been comprehensively discussed within stylistics and rhetoric until the emergence of cognitive linguistic studies which provided a whole new perspective on this phenomenon. According to Lakoff and Johnson (1980), metonymic concepts "allow us to conceptualize one thing by means of its relations to something else". The relation to something else or "belonging together" is what we refer to as contiguity relations. The different ways of 'belonging together' are called contiguity relations, which will be discussed in the passages to follow. Some other scholars refer to metonymy as "an embodied mental process occurring naturally and unconsciously as a result of synaptic links in the parts of the brain supporting mental and linguistic activities" (Bierwiaczonek, 2013:37)" or as to natural inference schemas, i.e. easily activatable associations among concepts that can be used for inferential purposes (Panther \& Thornburg, 2004).

A definition providing the sum of the cognitive nature of metonymy was provided by Langacker who illustrated metonymy as "a process 
which consists in mentally accessing one conceptual entity via another entity" (1993: 30). Speaking of metonymy and conceptual blending, Alac $\&$ Coulson inferred that metonymy does involve the conceptual blending of the concept evoked by the source term and the concept evoked by the intended target (2004). Among all the viewpoints of metonymy held by cognitive linguists, most of them concur those metonymy is a mental access to one conceptual entity via another. Hence, the conceptual blending helps us realize that the source concept does not simply vanish but is emerges in the meaning of the metonymic blend. It seems that the phenomenon of metonymy-based adjectives has been quite neglected when compared to metonymy-based nouns. On one side, it is understandable as adjectives are semantically dependant on the nouns they modify. Nevertheless, due to their attributive nature, adjectives offer many opportunities resulting in metonymic relations. Although metonymy-based epithets have been well accounted for in terms of stylistic studies, there seems to be plenty of space for linguistic reports.

\section{Conceptual Integration and Blending}

Speaking of conceptualization, two theories emerged within the domain of cognitive approaches - the Conceptual Metaphor Theory initiated by Lakoff and Johnson (1980) and the Theory of Mental Spaces which gave rise to the Theory of Conceptual Integration resulting from a joint venture by Fauconnier and Turner (1998, 2003). Lakoff and Johnson assumed that ,...the locus of metaphor is not in language at all, but in the way we conceptualize one mental domain in the terms of another." (Lakoff 2006: 185). Based on their observations, Conceptual integration theory was initiated in early 1990s only to be summed up by its authors in a 2002 work titled The Way We Think. According to them, "Conceptual blending is a basic mental operation that leads to new meaning" (Fauconnier and Turner, 2003). In Fauconnier's words, the Theory is based on the notion of mental spaces: "small conceptual packets constructed as we think and talk for purposes of local understanding and action ... partial assemblies containing elements ... structured by frames and cognitive models" (Fauconnier 2006: 662).

The role of domains from Conceptual Metaphor Theory was replaced by mental spaces in CIT. Still, these two notions do not represent counterparts - „...while domains (i.e. concepts, frames etc.) are stable 
and stored, mental spaces are transitory and ephemeral, and usually not memorized, though they can turn into stabilized semantic knowledge." (Kok, Bublitz 2011: 295). Unlike the Conceptual Metaphor Theory, CIT comprises of four mental spaces: two input spaces, generic space and the blend. The input spaces are similar to source and target domains as elements from both spaces are conceptually integrated. Generic space represents conceptual structure that is shared by both inputs and the blended space is where material from the two inputs combines and interacts. In the process, a mapping takes place in which an object or element in one mental space corresponds to an object or element in another.

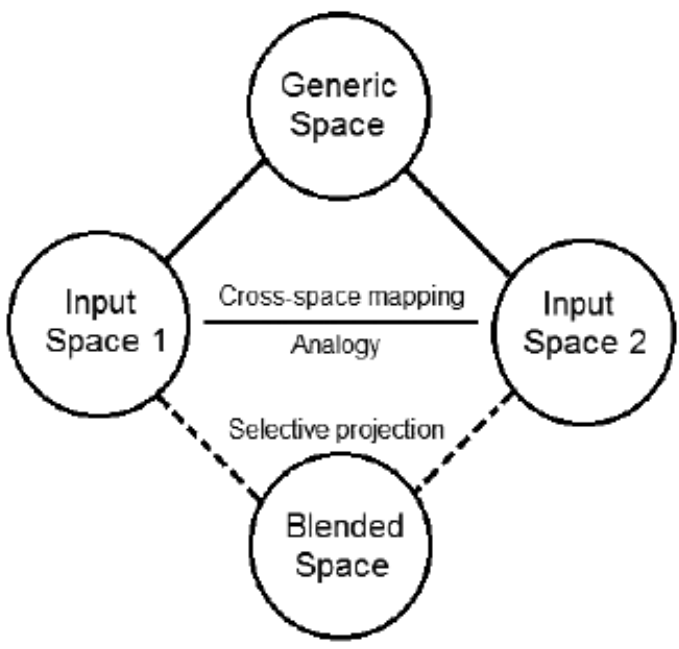

Figure 1. Schematic representation of conceptual blending (Fauconnier, 1997:51)

As Fauconnier (1994) points out, mental spaces are related through co referential identity as well as analogic, metaphoric and categorial cognitive mapping. Along with Turner, Faucconier came to a conclusion that integration networks achieve systematic compression. In other words, relations which connect different mental spaces may be "compressed into a representation relation or an identity relation within the integration network, such as in The Grim Reaper or Clinton and the Titanic" (Faucconier and Turner, 2008). The outcome is a blend rich in information and effectiveness as is the case with our metonymy-based compound epithets. "Crucially, the blended space remains connected to the inputs by the mappings, so that 
real inferences can be computed in the inputs from the imaginary situation in the blended space." (Faucconier and Turner, 2003: 59). In the paper, the focus will be on the fact that mental spaces are arranged sets with elements and their interrelations, open to new elements and relations. We shall attempt to account for these new elements in compound metonymybased epithets and see what happens when adjectives (epithets) are shifted from their ordinary nouns.

\section{The corpus}

Studies focused on adjectives commonly use dictionaries in order to provide the corpus to be analyzed. On the other hand, if we are to address epithets, we must draw to the English fictional discourse. The examples analyzed for the purpose of the paper emerged during an extensive reading of 6 contemporary fictional books by English/American authors. The aim was to single out examples of compound metonymy-based epithets which would be used as model instances of what we would refer to as discourse metonymy. The reason for this is that, unlike the ordinary and static metonymy (e.g. powerful throne), our examples completely depend on the context; they are highly unexpected and rely on the author's imagination and perception. Thus, the patterns used in the paper fully reflect creativity and mind of the writers as the "word combinations" fail to be found in dictionaries. One of few studies on noun compounding was conducted by Reka Benzces (2006), who provided an account of metaphorical and metonymical noun compounds in English claiming they were motivated by author's creativity. Still, metonymically-based adjectives dependant on the writer's creativity and imagination remain insufficiently addressed.

One of the shortcomings of our study is the limited number of valid examples of metonymy-based epithets as they highly depend on the writer's imagination, creativity and how often they use them. Still, there have been few cognitive linguistic reports on this phenomenon, which is why this paper might cast some light in terms of motivation for the usage of such epithets. The following passages aim to account for the semantic shifts that occur in these highly striking word coins in terms of the theory of mental spaces and conceptual integration (Fauconnier and Turner, 1994). We shall see what happens when the adjective is shifted from its ordinary noun and what the process results in. We suggest that the semantic shift results in powerful expressiveness. In the paper, the primary goal is twofold: 
a) firstly, we aim to see to which extent and how the conceptual integration theory may account for compound metonymy-based epithets

b) secondly, we shall demonstrate that compound-adjective part of the metonymical blend adds to the effective meaning.

\section{Metonymical mapping of metonymy-based epithets}

For the purpose of metonymical mapping of metonymy-based epithets the following examples will be used:

a) The man gave him a tobacco-stained smile. (Brown:109)

b) In Sexton's den, six entrepreneurs jumped up in wild-eyed horror. (Brown:292)

c) As if in slow motion, he set down the phone and stared in openmouthed wonder.(Brown:45)

d) A white-starched butler descended from an upper terrace and waited until the precautions were complete.(Forsyth:215)

e) Or there is dictatorship, a terrible tyranny to match anything your long-suffering country has ever seen.(Forsyth:299)

f) In all his red-faced glory, George Rathbun booms from the speakers.( King: 343)

\section{The tobacco-stained smile}

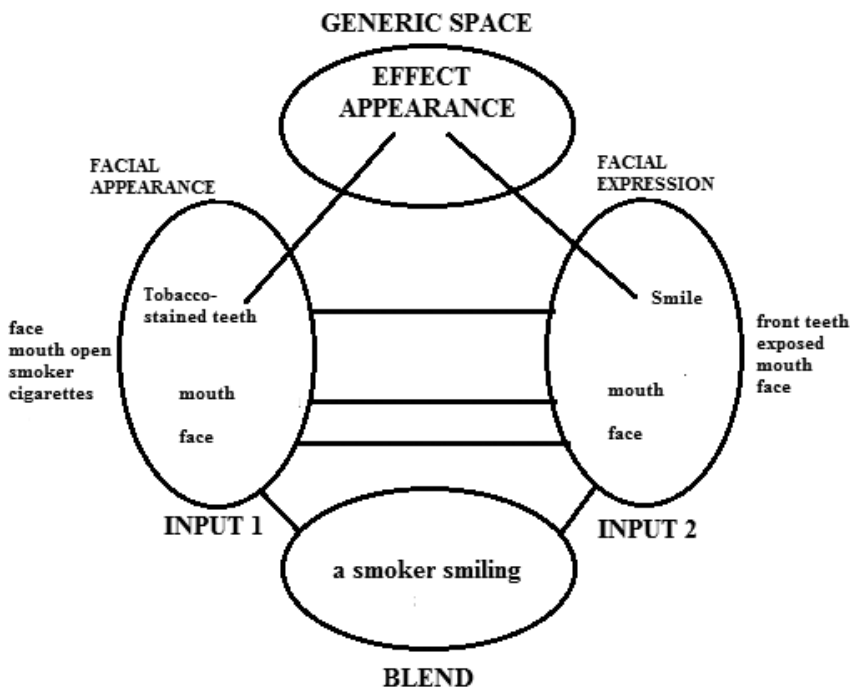


What happens with the integration networks in this example is that we have Input 1 which is the mental space "Human, facial appearance" and Input 2 which is the mental space "Human, facial expression". First, the structure of human facial appearance is described for Input 1 (mouth open, cigarettes, personal hygiene) and for Input 2 (front teeth exposed, mouth open, pleased, amused). Once we described the elements of the two inputs, the cross-mapping between the inputs occurs. Nevertheless, the projection we perform is selective and fragmentary because not all the elements from the two inputs are equivalent. The emergent structure in the blend is that people who make the facial expression of smiling commonly show their teeth, which in turn might be tobacco-stained if they are smokers. The blend construction is completed by metonymical projection from teeth to smile so it is the teeth that are stained with tobacco rather than the smile.

Wild-eyed horror

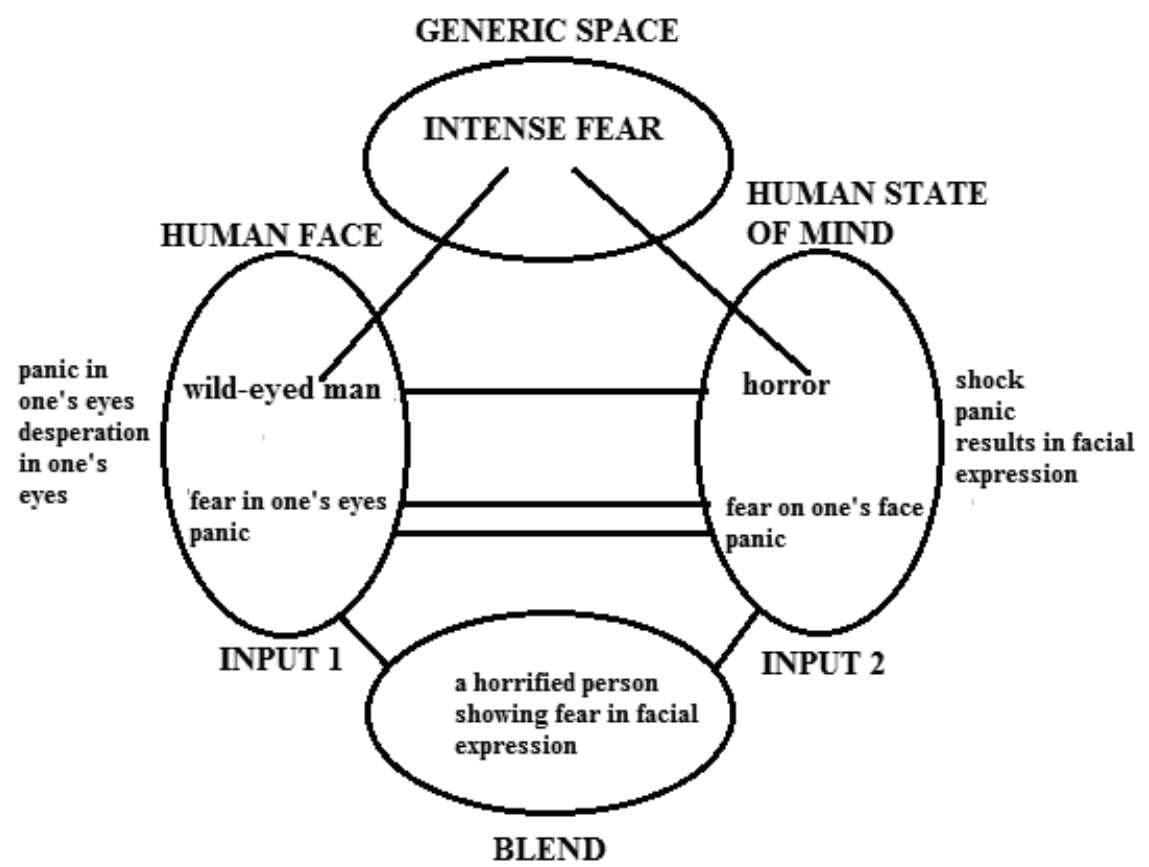

Again, there are two Inputs, i.e. different mental spaces, which result in a construction of a new mental space. The adjective wild-eyed belongs to the mental space "Human being, facial expression" whereas the noun 
horror belongs to the mental space "Human state of mind". The elements of both Inputs are singled out and the cross-mapping is performed. Even though both inputs belong to the mental space "Humans", they differ in that one draws to human facial expression and the other to the human state of mind. The opposition of the two inputs results in a highly expressive and effective metonymical blend in which it is the man who is wild-eyed and not the horror itself. After the metonymical projection from man to horror, the blend construction is completed. The compound adjective itself does not change its lexical category the meaning but rather shifts from its original noun resulting in a potent construction.

\section{Open-mouthed wonder}

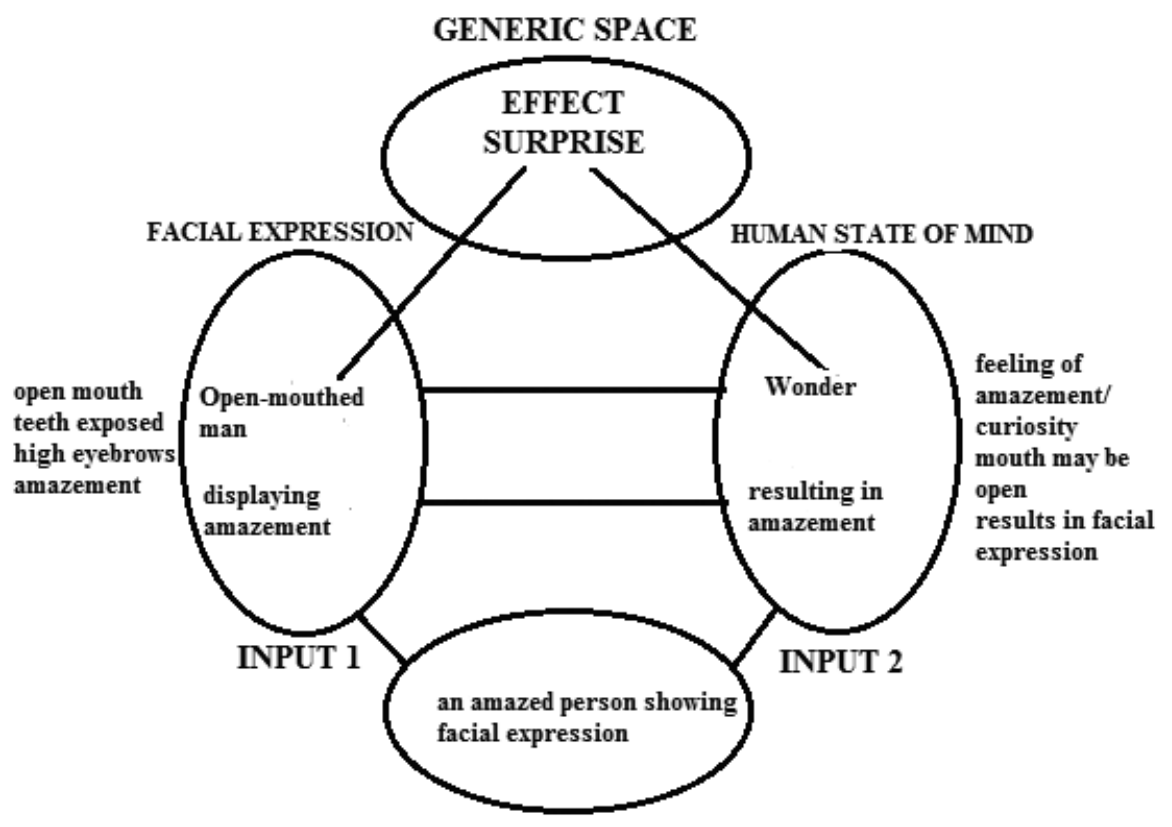

BLEND

In this construction, there is Input 1 within the mental space "Human being, facial expression" and Input 2 within the mental space "Human state of mind". The elements of human state of mind are being described (amazement, curiosity, mouth open) followed by the elements of facial expression of amazement (open mouth, eyes wide open). The selective projection is performed after which the blend structure emerges. The 
metonymical projection from man to wonder occurs so the new blend means that it is actually the man who is open-mouthed and not the wonder. The opposed mental spaces of Human facial expression and Human state of mind yet again generate a highly vivid construction.

\section{White-starched butler}

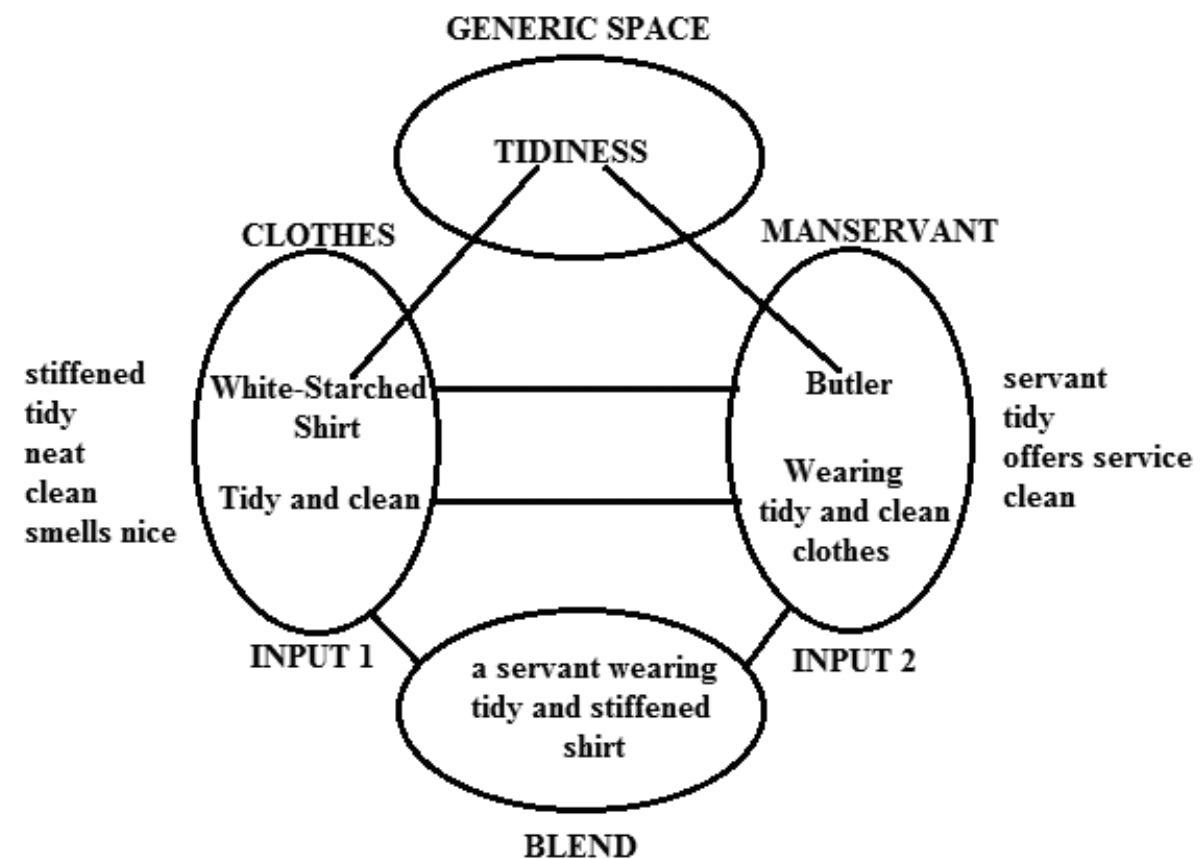

The two Inputs are from different mental spaces, "Clothes" and "Human, manservant", respectively. After the elements from both mental spaces are singled out, the selective projection results in a blend structure describing a person wearing a tidy, stiffened shirt. The metonymical projection from shirt to butler tells us that it is the shirt the he is wearing is starched and not the butler himself. The opposition between the two mental spaces created a highly vibrant and striking utterance. 


\section{Long-suffering country}

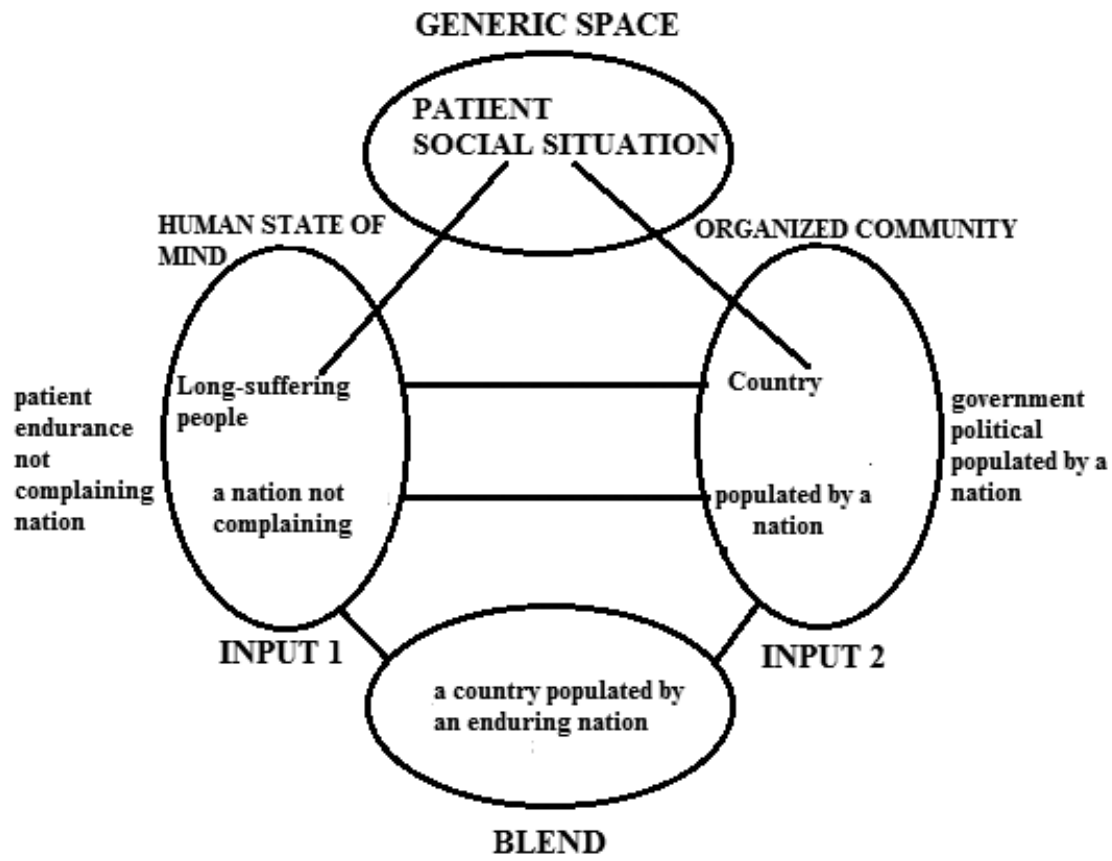

In the example, there is Input 1 within the mental space "Human state of mind" and Input 2 within the mental space "Organized community". The generic space representing commonalities between the two inputs indicates a social situation. After the inputs are described and common elements are extracted, the pivot construction emerges. The cross-mapping generates a structure which tells us that it is an organized community populated by patient and enduring people. So the metonymical projection illustrates that it is the people who are long-suffering and not the political organized community. In addition, the metonymical relation rises from the external connection between the subject (country) and the part/member (people). 


\section{Red-faced glory}

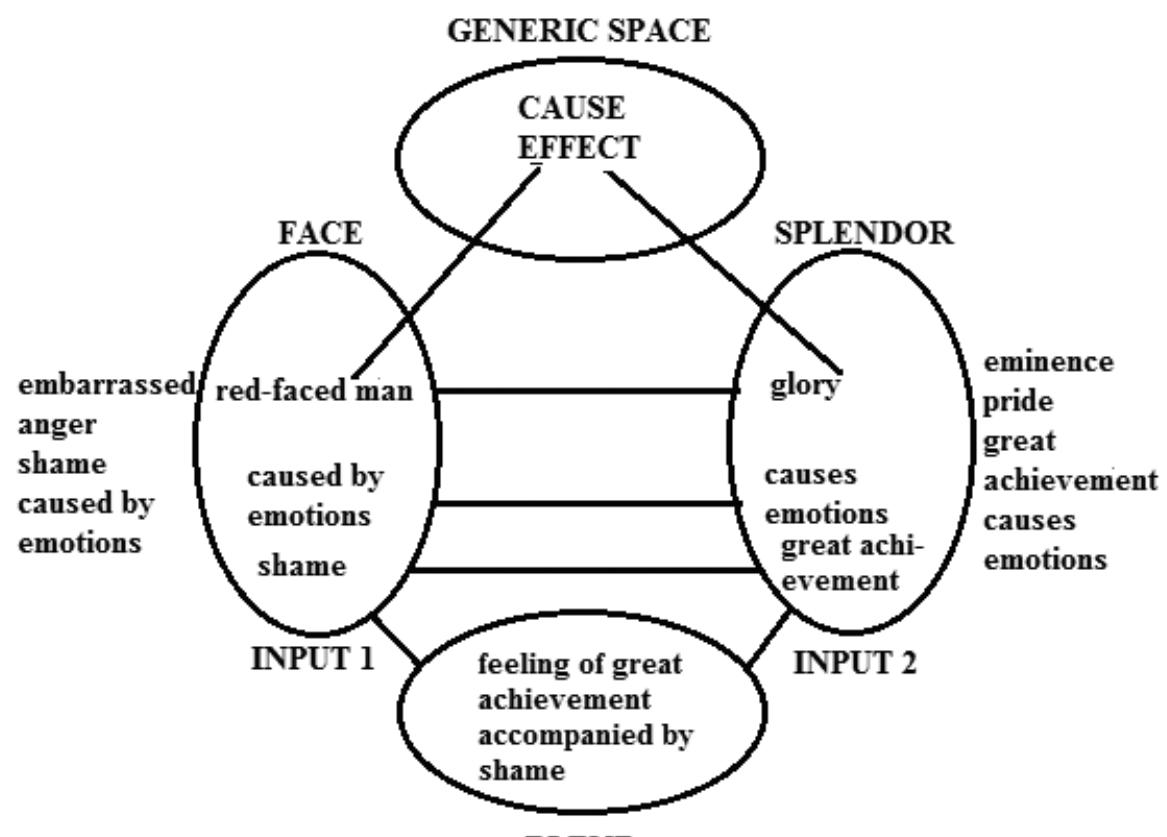

BLEND

The generic space in this example specifies feeling of embarrassment. The integration network works like this: one input is the mental space "Face complexion" and the other input is the mental space "Splendor". After the structure of both inputs is accounted for, the cross-mapping occurs. The projection is once more fragmentary and selective and the emergent structure suggests that people may have the feeling of great accomplishments accompanied by embarrassment. Once the blend construction is completed by metonymical projection from man to glory, we understand that it is the man who are red-faced and not the glory itself. Yet again, the pivot blend structure generated a highly vivid and expressive utterance.

\section{Final remarks}

The previous section attempted to account for the metonymical mapping of metonymy-based epithets. We saw that emergent blend structures resulted in highly expressive and efficient utterances typical of fictional discourse. What happened after the adjective was shifted from 
its original noun was a new contextual meaning. In all these metonymical blends, the adjectives do not change their lexical category but rather shift from their original nouns. They syntactically correspond with the noun they modify but semantically they refer to another noun. Consequently, the original noun is being either implied or reallocated in the sentence. We saw that all our metonymy-based epithets shift from entity 1 to entity 2 . In open-mouthed wonder, open-mouthed shifted from entity 1 (man) to entity 2 (wonder); in white-starched butler, white-starched shifted from entity 1 (shirt) to entity 2 (butler), etc. The epithets, i.e. the adjectives functioning here as epithets, do not change their grammatical class.

We also saw that these highly effective constructions are only more empowered by the nature of compound adjectives which are themselves expressive enough but only add to the already figurative meaning. Speaking of transferred epithets, or of what we refer to as metonymybased compound epithets, a blood-thirsty axe is certainly more effective than a scornful eye and a wild-eyed horror evokes a more bombastic effect than $a$ weary road. It is exactly the nature of compound adjectives that allows more information than in the case of single adjectives. Hence, they tend to be more vivid in descriptions and they represent a potent addition to already figurative and expressive epithets such as those based on metonymy. As compound adjectives represent eye-catching constructions packed with ample meanings, they help fictional writers achieve pompous effects when they are used in metonymical blends.

Finally, we met our primary goals in terms of applicability of CIT to compound metonymy-based epithets. We saw that cross-mapping is an excellent means to clarify and illustrate how metonymy-based epithets are created. Once the structure of both inputs is described, the cross-mapping between two input spaces occurs. What is interesting is the fragmentary and selective projection as not all the elements from the two input structures must concur. The emergent structure in the blend helps us understand the hidden connection between the modified noun and the one implied. Finally, the construction is completed by metonymical projection which results in an effective utterance.

Once we account for the motivation and creation of metonymybased epithets and how they work, we may actually better understand the writer's intentions. Then, they no longer appear to be so vague and our perception may not be so distant from the author's. 


\section{REFERENCES}

Alac, M. and S. Coulson (2004). The Man, the Key, or the Car: Who or What Is Parked out Back? Cognitive Science Online, Vol: (2): 21-34

Barancheeva, E.I. (2016). Semantic mechanisms of transferred epithet in English. Novosibirsk State Pedagogical University Bulletin . Vol. 30 Issue 2, 94-103

Beckson, K. and A. Ganz. (1960). A reader's guide to literary terms. New York: Noonday Press

Benczes, R. (2006). Creative compounding in English: the semantics of metaphorical and metonymical noun-noun combinations. Amsterdam: John Benjamins.

Bierwiaczonek, B. (2013). Metonymy in Language,Thought and Brain. Sheffield: Equinox

Cuddon, J. A. (1979). A Dictionary of Literary Terms. Great Britain: W and J Mackay Limited

Fauconnier, G. (1994). Mental spaces. New York: Cambridge University Press.

Fauconnier, G. (1997). Mappings in Thought and Language. Cambridge, U.K.: Cambridge University Press.

Fauconnier, G. (2006). Pragmatics and Cognitive Linguistics. In Laurence R. Horn \& Ward, Gregory L. (eds.), Malden, MA, Oxford: Blackwell. 658674.

Fauconnier, G and M. Turner (2003). Conceptual Integration. Shanghai: Foreign Languages .

Fauconnier, G and M. Turner (1994). Conceptual Pr ojection and Middle Spaces. Technical Report no. 9401. Department of Cognitive Science, University of California, San Diego.

Fauconnier, G and M. Turner(1998). Conceptual Integration Networks. Cognitive Science 22:2. 133- 187.

Fauconnier, G. and M. Turner (2003). Conceptual blending, form and meaning. Rech. Commun.19, 57-86.

Fauconnier G. and M. Turner (2008). Rethinking Metaphor. In Ray Gibbs, ed. Cambridge Handbook of Metaphor and Thought. Cambridge University Press.

Galperin, I. R. (1977). Stylistics. MOSCOW "HIGHER SCHOOL"

Караваева Н.А. (2009). СТИЛИСТИКА АНГЛИЙСКОГО ЯЗЫКА. ИНСТИТУТ СОЦИАЛЬНЫХ И ГУМАНИТАРНЫХ ЗНАНИЙ. Казань

Kok, S. and W. Bublitz (2011). "Conceptual blending, evaluation and common 
OPEN-MOUTHED WONDER - AN ACCOUNT OF METONYMY-BASED ...

ground: George W. Bush and Saddam as friend or foe?", in Handl, S. \& H.-J. Schmid (eds). Windows to the Mind. Metaphor, Metonymy and Conceptual Blending. (Cognitive Linguistics Research 48). Berlin/Boston: De Gruyter. 291-309.

Lakoff, G. (2006). Whose Freedom? The Battle over America's Most Important Idea. New York: Farrar, Straus and Giroux.

Lakoff, G. and M. Johnson (1980). Metaphors We Live By. Chicago and London: The University of Chicago Press.

Langacker, R. W. (1993). Reference-Point Constructions. Cognitive Linguistics, 4, 29-40.

Lanham, R. A. (1991). A Handlist of Rhetorical Terms. USA: University of California Press.

Panther, K.U. and L. L. Thornburg. (2003). Metonymies as natural inference and activation schemas: Th e case of dependent clauses as independent speech acts. In Panther, K.U. and L. L. Th ornburg. (Eds.). Metonymy and Pragmatic Inferencing,. Amsterdam/Philadelphia: John Benjamins Publishing Company. 127-147.

Sakran N. (2005). A Stylistic Analysis of Compound Epithets in Shakespeare's Romeo and Juliet. Journal of the College of Arts. University of Basrah No. (38)

Shibuya, Y. (2006). On transferred epithet: a constructionist approach. Proceedings of the 2006 Seoul International Conference on Linguistics: 229-238.

Simpson, P. (2004). Stylistics. Routledge.

\section{SOURCES}

Brown, D. (1998). Digital fortress. New York: St. Martin's Press.

Brown, D. (2000). Angels and demons. New York: Pocket Books.

King, S. (2001). Black House. New York: Gallery Books

Forsyth, F. (1996). Icon. New York: Bantam books.

Forsyth, F. (2003). Avenger. New York: Bantam books. 


\section{Nevena Ž. Vučen Papić}

\section{OPEN-MOUTHED WONDER - O EPITETIMA U FORMI SLOŽENICE ZASNOVANE NA METONIMIJI}

\section{Sažetak}

Mada su složeni epiteti čest predmet izučavanja retoričkih i stilističkih studija, mali je broj radova koji se bave ovim konstrukcijama u slučajevima gdje postoje očigledni metonimijski odnosi. Cilj rada je da objasni motivaciju tvorbe ovakvih složenica primjenjujući teoriju konceptualne integracije. Osnovni cilj je prikaz mapiranja mentalnih prostora kod metonimijskih složenih epiteta pri čemu je naglasak na epitetima kod kojih lijevi constituent čine isključivo složeni pridjevi. Osim toga, pokazaćemo kako upravo složeni epiteti doprinose ekspresivnosti metonimijskih složenica u ciljnom diskursu. 